\title{
Efektivitas Promosi Kesehatan Menggunakan Media Audiovisual Terhadap Keaktifan Lansia ke Posyandu Lansia
}

\author{
Sri Astutik Andayani', Husnul Khotimah², Sry Desy ${ }^{3}$, \\ Arif Eko Trilianto ${ }^{4}$, Hefniy Razaq ${ }^{5}$ \\ ${ }_{1}^{1}$ Universitas Nurul Jadid \\ email:astutikandayani86@gmail,com \\ 2Universitas Nurul Jadid \\ email:husnulcrakers@gmail.com \\ 3Universitas Nurul Jadid \\ email:Sridesylailatulrisqi11@gmail.com \\ ${ }^{4}$ Dinas Kesehatan Probolinggo \\ email:arif.trilianto@gmil.com
}

\section{Abstract}

Implemented posyandu elderly there are obstacles that often faced is low visit, one of cause factor is low of knowledge of elderly so that beneficiary of posyandu elderly still not maximal. The purpose of this research is to know the influence of health promotion about elderly posyandu by use audio visual media toward liveliness of elderly in following elderly posyandu. The design use in this research is Quasy Experimental with pretest-posttest with control design. This research was conducted at Maesan Bondowoso health center with 55 respondents with total sampling technique. This analysis used Wilcoxon and Mann-Whitney test. The results showed that health promotion was effective to increase the member of ekderly visit to the elderly health center with $p$ value 0,000.

Keywords : Health Promotion, Elderly Health Centre, elderly active 


\section{Abstrak}

Pelaksanakan posyandu lansia kendala yang sering dihadapi yakni rendahnya kunjungan lansia ke posyandu, salah satu faktor penyebabnya adalah rendahnya pengetahuan lansia sehingga pemanfaat posyandu lansia masih belum maksimal. Tujuan dari penelitian ini untuk mengetahui pengaruh promosi kesehatan tentang posyandu lansia dengan menggunakan media audio visual terhadap jumlah kunjungan lansia ke Posyandu. Penelitian ini menggunakan metode Quasi Eksperimental dengan pendekatan pretestposttest with control Design. Penelitian ini dilakukan di Puskesmas Maesan Bondowoso sejumlah 55 responden dengan teknik total sampling, analisa data yang digunakan adalah Uji Wilcoxon dan Man Whitney. Hasil penelitian menunjukkan bahwa Promosi kesehatan dengan media Audio Visual efektif untuk meningkatkan keaktifan lansia dalam posyandu dengan nilai $\mathrm{p} 0,000$.

Kata kunci Promosi Kesehatan, Posyandu Lansia, Keaktifan 
Pendahuluan

Keaktifan

lansia

datang ke Posyandu Lansia adalah suatu frekuensi keterlibatan dan keikutsertaan dalam mengikuti kegiatan posyandu secara rutin setiap bulan dan merupakan salah satu bentuk perilaku kesehatan Lansia dalam upaya memelihara dan meningkatkan kesehatan dirinya secara optimal. Faktor penentu atau determinan perilaku manusia sulit untuk dibatasi karena perilaku merupakan kumpulan dari berbagai faktor baik internal maupun eksternal (lingkungan) (Depkes, 2006).

Motivasi seseorang dalam pemilihan atau datang ke fasilitas kesehatan di pengaruhi oleh faktor persepsi atau pengetahuan (Andayani, 2017).

Pengetahuan lansia dapat di pengaruhi oleh faktor seperti budaya, kebiasaan, dan pengalaman hidup. Pendidikan merupakan suatu bentuk intervensi yang di tujukan kepada perilaku, agar perilaku tersebut dapat berpengaruh positif terhadap peningkatan kesehatan (Notoatmodjo, 2012). Hal tersebut sejalan dengan hasil pendidikan terakhir lansia yang bisa mempengaruhi

pengetahuan proses belajar, karena semakin tinggi pendidikan seseorang maka akan semakin mudah orang tersebut untuk menerima informasi (Koentjaraningrat, 2009).

Peningkatan pengetahuan lansia dapat di tingkatkan dengan model health promotion atau yang biasa di sebut promosi kesehatan yang merupakan model bagi perawat untuk mengeksplorasi proses biopsikososial yang kompleks, yang 


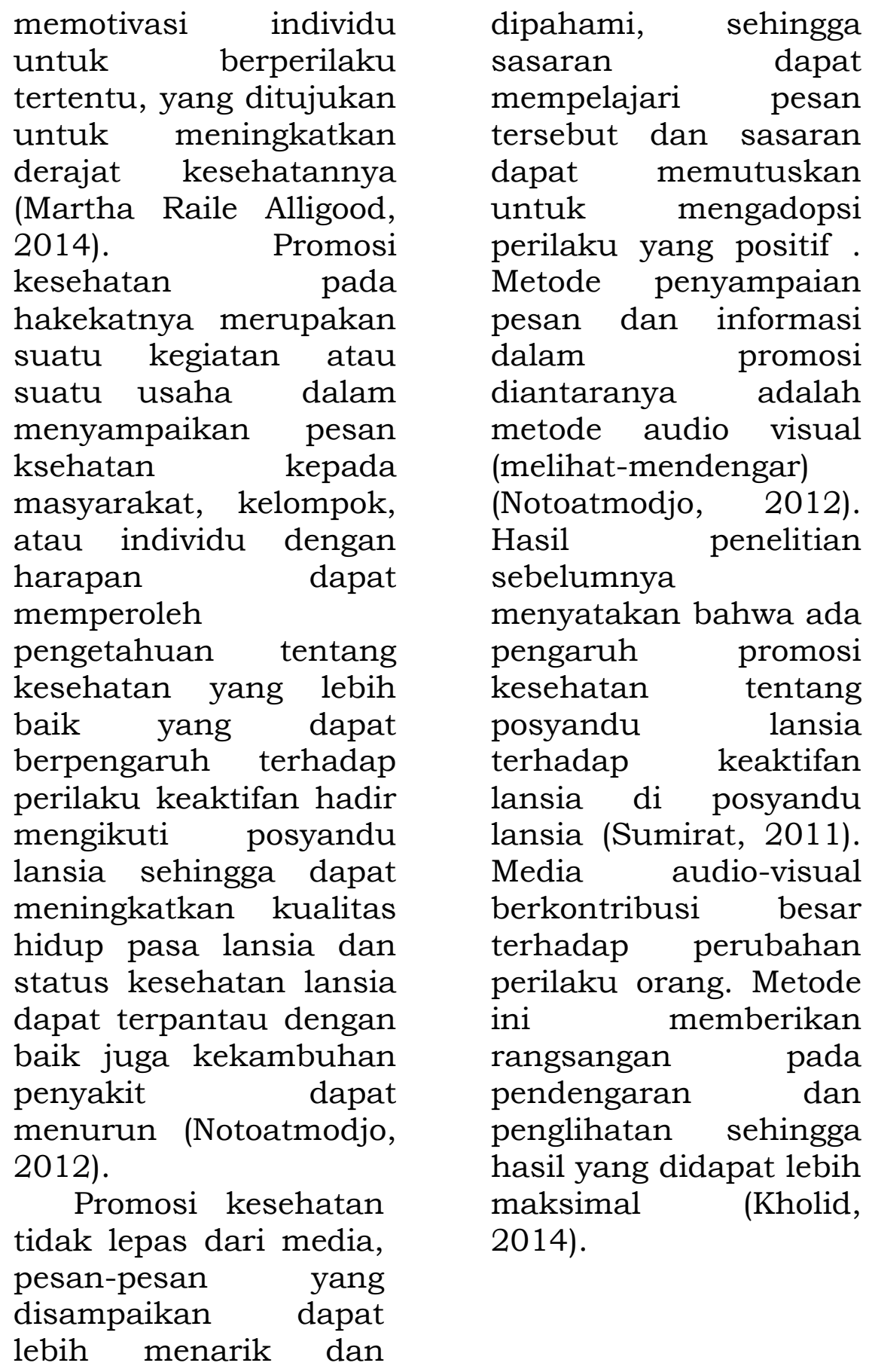


Sri Astutik Andayani: Promosi Kesehatan

Metode

Design penelitian yang digunakan adalah Quasi Eksperimental dengan menggunakan rancangan pretestposttest with control Design. Subyek penelitian ini berjumlah 55 responden yang dihasilkan dari tehnik pengambilan sampling yaitu totally sampling. Penelitian ini menggunakan analisis univariat dan bivariat. Untuk analisis univariat menggunakan distribusi frekuensi. Analisis bivariat yaitu uji statistic Wilcoxon sign rank test dan dengan bantuan SPSS untuk menganalisis perbedaan antara sebelum dan sesudah dilakukan perlakuan pendidikan kesehatan dan skala data yang digunakan dalam bentuk ordinal.

\section{Hasil Penelitian}

Berdasarkan penelitian didapatkan hasil sebagai berikut:

Tabel 1
Distribusi frekuensi karakteristik responden $(\mathrm{n}=55)$

Karakteristik Jumlah prosentase

\begin{tabular}{lll} 
Responden & $\mathrm{n}$ & $\%$ \\
\hline 1. Usia &
\end{tabular}

60 Tahun

$9 \quad 16,4 \%$

61 Tahun

7

$12,7 \%$

62 Tahun

$8 \quad 14,5 \%$

63 Tahun

7

$12,7 \%$

64 Tahun

10

$18,2 \%$

\begin{tabular}{lll}
65 Tahun & 14 & $25,5 \%$ \\
\hline Total & 55 & $100 \%$
\end{tabular}

2. Jenis kelamin

\begin{tabular}{lll} 
Laki-laki & 29 & $52,7 \%$ \\
Perempuan & 26 & $47,3 \%$ \\
\hline Total & 55 & $100 \%$ \\
\hline
\end{tabular}

3. Pekerjaan

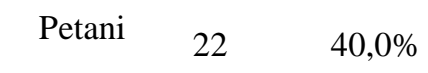

Ibu Rumah

Tangga $23 \quad 41,8 \%$

$\begin{array}{lll}\text { Pedagang } & 6 & 10,9 \%\end{array}$

Pensiun $\quad 4 \quad 7,3 \%$

$\begin{array}{lll}\text { Total } & 55 & 100 \%\end{array}$


Sri Astutik Andayani: Promosi Kesehatan

Tabel 2

Keaktifan sebelum dan sesuadah diberikan Promosi kesehatan

\begin{tabular}{|l|c|c|c|c|c|}
\hline Variabel & \multicolumn{2}{|c|}{ Pre } & \multicolumn{2}{c|}{ Post } & $\begin{array}{c}\text { P } \\
\text { value }\end{array}$ \\
\hline & $\begin{array}{l}\text { Mean } \\
\text { Rank }\end{array}$ & SD & $\begin{array}{c}\text { Mean } \\
\text { Rank }\end{array}$ & SD & \\
\hline $\begin{array}{l}\text { Kelompok } \\
\text { Kontrol }\end{array}$ & 6,81 & 0,921 & 6,78 & 0,698 & 0,834 \\
\hline $\begin{array}{l}\text { Kelompok } \\
\text { Perlakuan }\end{array}$ & 6,82 & 0,723 & 17,07 & 1,052 & 0,000 \\
\hline
\end{tabular}

Dari tabel diatas dapat dilihat bahwa pada kelompok kontrol hasil uji statistik Wilcoxon didapatkan nilai $\mathrm{P}$ Value sebesar 0,834 tidak ada pengaruh kesehatan keaktifan posyandu sedangkan kelompok didapatkan 0,000 yang bermakna bahwa ada pengaruh promosi kesehatan terhadap keaktifan mengikuti posyandu lansia

Tabel 3

Pengaruh Promosi Kesehatan Terhadap Keaktifan Lansia

\begin{tabular}{|l|l|l|l|l|}
\hline \multirow{2}{*}{} & \multicolumn{2}{|c|}{ Keaktifan } & Perbedaan & $\begin{array}{l}\text { P } \\
\text { Value }\end{array}$ \\
\cline { 2 - 5 } & Eksp. & kontrol & & \\
\hline Sebelum & 28,75 & 27,22 & 0,01 & 0,699 \\
\hline Sesudah & 41,50 & 14,00 & 10,29 & 0,000 \\
\hline
\end{tabular}

Dari tabel diatas dapat dilihat bahwa hasil uji statistic Mann Whitney Test sebelum di lakukan promosi kesehatan pada kelompok eksperimen dan kontrol memiliki nilai $P$ sebesar 0,699 sedangkan sesudah dilakukan promosi kesehatan pada kelompok eksperimen dan kontrol memiliki nilai $p$ sebesar 0,000 . Sehingga dapat disimpulkan bahwa terdapat perbedaan antara kelompok eksperimen dan kontrol sebelum maupun setelah dilakukan promosi kesehatan.

\section{Pembahasan}

\begin{tabular}{lr}
\multicolumn{2}{c}{ Berdasarkan } \\
hasil penelitian \\
menunjukkan & ada \\
pengaruh & promosi \\
kesehatan & dengan \\
menggunakan & media \\
audio visual terhadap \\
keaktifan lansia dalam \\
mengikuti & posyandu \\
lansia. Hal & senada \\
penelitian & (Wigati, \\
2011) menyatakan ada \\
pengaruh & pendidikan \\
kesehatan & tentang
\end{tabular}


Sri Astutik Andayani: Promosi Kesehatan

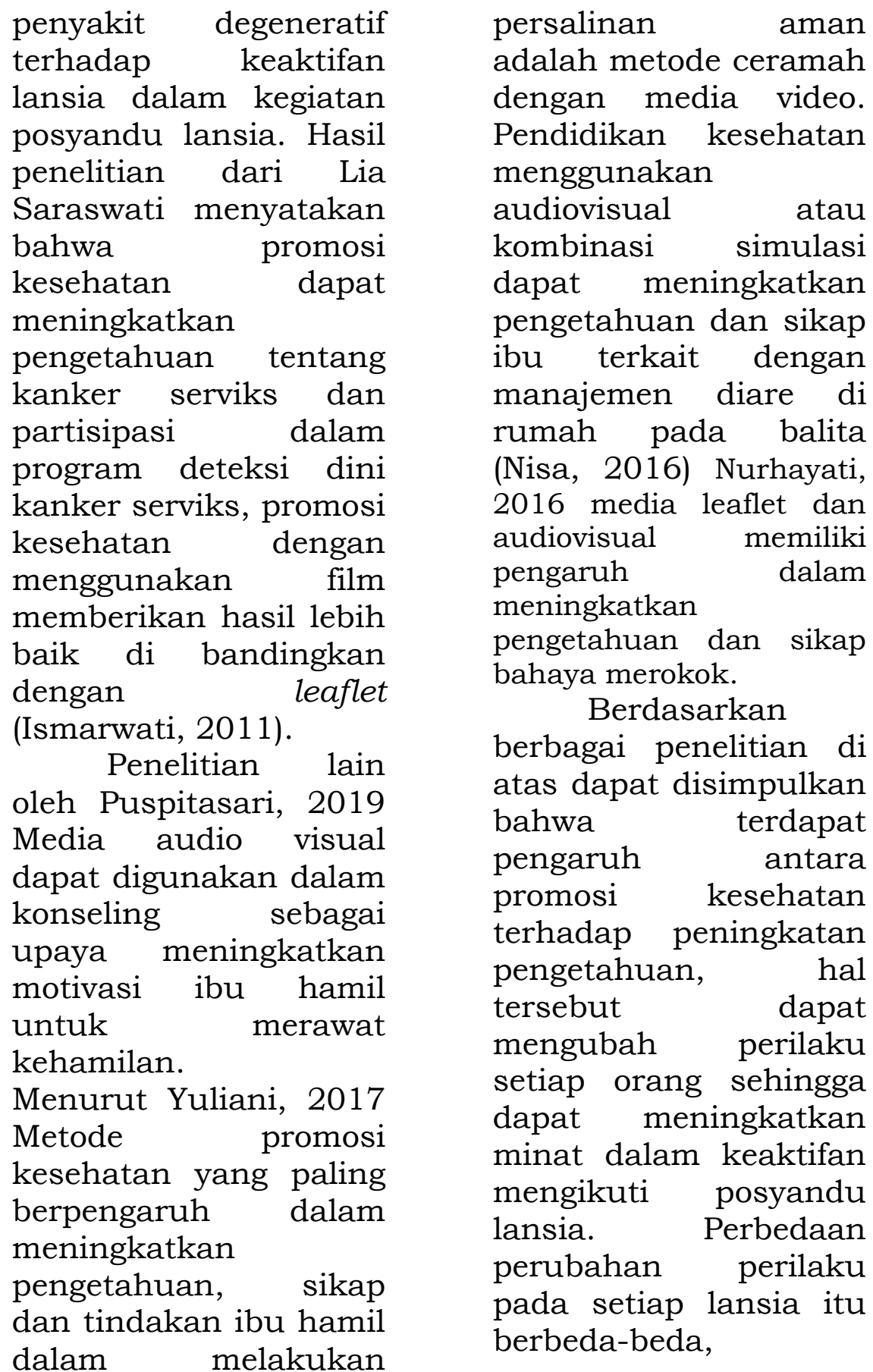


dikarenakan

mengalami

faktor

adalah

terkait

kesadaran dari masingmasing lansiajuga yang berhubungan dengan tingkat pendidikan, pemahaman terkait posyandu lansia dan juga lingkungan tingkat tinggal.

Berdasarkan

berbagai penelitian di atas dapat disimpulkan bahwa terdapat pengaruh antara promosi kesehatan terhadap peningkatan pengetahuan, tersebut

hal mengubah perilaku mengubah perilaku setiap orang sehingga dapat meningkatkan minat dalam keaktifan mengikuti posyandu lansia. Perbedaan perubahan perilaku pada setiap lansia itu berbeda-beda, dikarenakan

mengalami banyak faktor diantaranya adalah perbedaan terkait usia dan kesadaran dari masing- masing lansiajuga yang berhubungan dengan tingkat pendidikan, pemahaman terkait posyandu lansia dan juga lingkungan tingkat tinggal.

\section{Simpulan}

Hasil uji Mann-Whitney pada pengaruh promosi kesehatan keaktifan dalam terhadap mengikuti posyandu lansia di dapatkan nilai signifikansi sebesar 0.000 $(\mathrm{p}<0.05)$ yang berarti terdapat peningkatan keaktifan dalam mengikuti posyandu lansia pada kelompok eksperiman bandingkan dengan kelompok kontrol sebelum dan setelah dilakukan promosi kesehatan 
Sri Astutik Andayani: Promosi Kesehatan

Daftar Pustaka

Alligood, M. R. (2014).

Nursing theory \& their work $\left(8^{\text {th }}\right.$ ed). The CV Mosby.

Amalia Indah

Puspitasari, 2019. The Effect of Audiovisual

Counseling of Conception Period and Nutrients to the Nutrient Improvement

Motivation on Pregnant Mothers at Primary Health Center Girisubo Gunungkidul Yogyakarta in 2015. KnE Life Science.

Aprilia Choirun Nisa dkk.2016. Effect of combination health education of simulation methods and audiovisual media to mothers' knowledge and attitude related to diarrhea management at

home in toddlers.

Company St. Louis. Toronto. Missouri: Mosby Elsevier. Inc.

Departemen Kesehatan RI. 2010. Pedoman Puskesmas Santun Lanjut Usia Bagi Petugas Kesehatan. Jakarta: Direktorat Bina Kesehatan Komunitas.

Ismarwati, dkk. 2011. Promosi Kesehatan dalam

Meningkatkan

Pengetahuan, Sikap dan Perilaku

Deteksi Dini Kanker Serviks pada Ibu-Ibu Anggota Pengajian. Berita Kedokteran Masyarakat. Vol. 27.No.2 Juni 2011.

Kholid, Akhmad.

Promosi Kesehatan. $2014 . \quad J a k a r t a:$ Rajawali Pers. 
Sri Astutik Andayani: Promosi Kesehatan

Koentjaraningrat. 2009.

Pengantar Ilmu

Tentang Persalinan

Antropologi.

Jakarta:

RinekaCipta.

Aman.Jurnal

Ilimiah PANNMED.

Vol.11.No.3 Januari

2017.

Nugroho, W. 2000.

Keperawatan

Gerontik. Jakarta :

EGC

Notoatmodjo. 2007.

Promosi Kesehatan

dan Ilmu Perilaku.

Jakarta: PT Rineka

Cipta.

Putri Wahyu Wigati. $2011 . \quad$ Tesis.

Pengaruh

Pendidikan

Kesehatan Penyakit

Degeneratif

Terhadap Keaktifan

Lansia Dalam

Kegiatan Posyandu

Lansia. Universitas

Sebelas Maret

Surakarta.

Depkes. (2006). Buku Pedoman Umum

Pengelolaan

Posyandu. Jakarta.

Pengaruh Promosi

Kesehatan Dengan

Metode Ceramah

dengan Media

Video Terhadap

Perilaku Ibu Hamil

Andreas Dwi

Atmoko;Zainal

Munir;Gilang

Ramadhan. (2019).

PENGARUH

MENONTON

TAYANGAN

TELEVISI

TERHADAP

PERILAKU

AGRESIF PADA

ANAK

PRASEKOLAH

Andreas.

Keperawatan

Profesional, 7(1).

Retrieved from

https:/ / ejournal.un

uja.ac.id/index.php

/jkp/index\%OAPEN

GARUH

Restu Yuliani, 2017.

Pengaruh Promosi

Posyandu. Jakarta.

Firse Nurhayati, Sri Astutik Andayani, Vivin Nur Hafifah, K. R. (2016). 
Sri Astutik Andayani: Promosi Kesehatan

Perbedaan Promosi

Kesehatan dengan

Leaflet dan Audio

Visual terhadap

Pengetahuan dan

Sikap Bahaya

Rokok pada Siswa

SMP. Humaniora, 13(1).

Koentjaraningrat.

(2009). Pengantar Ilmu Antropologi. RINEKA CIPTA.

Martha Raile Alligood. (2014). Nursing theorists and their work. In Doris D Coward (Ed.), Nursing theory (8th ed., p. 574). United States of America: Elsevier Inc.

Notoatmodjo, S. (2012).

Promosi Kesehatan

Dan Perilaku

Kesehatan. jakarta: Rineka Cipta.

Saraswati, L. K. (2011). Pengaruh promosi kesehatan terhadap pengetahuan tentang kanker serviks dan partisipasi wanita dalam deteksi dini kanker serviks Di Mojokerto RW 22 Surakarta.

Sumirat, W. (2011). Pengaruh promosi kesehatan tentang posyandu lansia terhadap keaktifan lansia di posyandu lansia, 2(4), 45-51. 